\title{
Editorial vol 16, no 1: Online learning technologies
}

\author{
Arthur Tatnall
}

Published online: 16 December 2010

(C) Springer Science+Business Media, LLC 2010

In recent years online learning technologies have become a major part of the IT infrastructure of most universities and many schools around the world. While this technology has long been used in distance education it is now coming to be used more and more in other settings, and the issue of blended learning has become most important. Social networking is blossoming and aspects of this are also coming to be seen as valuable tools in education. The articles in this issue concentrate on distance learning, social networking and various different modes of e-learning. These topics fall within the ambit of IFIP Working Group 3.6-Distance Education.

The first article in this issue is by Benlihan Uğur, Buket Akkoyunlu and Serap Kurbanoğlu from Hacettepe University, Turkey and addresses the issue of: Students' Opinions on Blended Learning and its Implementation in Terms of their Learning Styles. In the article the authors examine students' views on blended learning. They look at this in relation to the students' individual learning styles. Web-based media contrasted with face-to-face classroom settings were used in the study with 31 senior students of a blended learning framework. Kolb's Learning Style Inventory, PreInformation Forms and open-ended questions were used to gather data.

The next article: Distance Learning Technology and Service Support in Greecethe Case Study of the Aristotle University Over the Last Decade by Angeliki Agorogianni, Zaharias Zaharis, Sofia Anastasiadou and Sotirios Goudos describes the distance-learning environment of the Aristotle University of Thessaloniki, Greece. Distance-learning classrooms have been used successfully over the last decade and the technical infrastructure is based on synchronous facilities. The article presents a generic data model for distance-learning service provision and describes how supplementary services have also been developed to provide support. Pedagogical issues in relation to both students and teachers have been investigated using statistical surveys.

Juliet Stoltenkamp and Okasute Akwega Kasuto from the University of the Western Cape, South Africa present an article entitled: E-Learning Change

\footnotetext{
A. Tatnall $(\bowtie)$

Victoria University, Melbourne, Australia

e-mail: Arthur.Tatnall@vu.edu.au
} 
Management and Communication Strategies within a HEI in a Developing Country: Institutional Organisational Cultural Change at the University of the Western Cape. Their paper reports on the strides that University of the Western Cape (UWC) has achieved in the adoption of e-learning strategies among academics from across different faculties in the campus community to supplement their traditional face-to-face teaching. Case study methodology in conjunction with documentary analysis was used in the study to highlight the achievements and challenges encountered in the adoption and implementation of the existing home grown open source e-learning system. The authors describe how a multi-dimensional noncoercive e-learning implementation approach was used, highlighting the various communication and change management strategies that the institution has employed in its endeavours to achieve broad e-learning buy-in within a resistant environment. A generic Instructional design model was developed to portray a continuum in the support for a changing organisational culture.

An article by Camilla Jonsson from Umeå University, Sweden then asks: Are Online Communities for Young People an Issue for Education Researchers? A Literature Review of Swedish and International Studies within the Educational Field. She asserts that issues concerning children and young people are of interest as question about fostering, up-bringing, learning and socialisation are core topics for academic researchers in education, and she notes that people in Sweden, and around the world, spend a large amount of their time in online communities or social networking sites. The article questions whether educational researchers currently contribute to this topic and argues that few academic studies do deal with youth and their online environments. The article concludes that this area is one where educational expertise is lacking and that online activity for children and young people is a topic currently lying outside the educational research field and that further research is required.

E-learning in Life Long Education: A Computational Approach to Determining Listening Comprehension Ability, by Cem Iș1k \& Sümeyra Y1lmaz from Turkey, suggests that e-learning, which is the use of telecommunication technology to deliver information for education and training, is emerging as the new paradigm of modern education. They note that because of the increasing amount of technology integration in the learning environment, more and more studies focus on examining "how people learn with technology". Their study was conducted to find out how computer assisted language learning contributes to learners' ability to develop listening comprehension.

The Formalization and Implementation of Eliminating and Optimizing Selection (EOS) approach by Marwah Alian from Isra Private University, Jordan is next. This article suggests that the main challenge of e-learning systems is to provide different courses to different students with different learning abilities, and that such systems must also be efficient and adaptive. Alian suggests that adaptivity can be accomplished by improving the ability to select dynamically an appropriate learning object for a specific learner. A framework for individualised learning object selection, called Eliminating and Optimizing Selection is analysed, implemented and used in experimentation and a formalisation for this framework has been suggested.

This issue has articles from Greece, South Africa, Sweden, Turkey and Jordon but it would be good to see more articles also from the developing parts of the world. As 
Editor-in-Chief of this journal I am keen to see articles on all aspects of the use of Information Technologies in Education from the micro to the macro and from theory to practice. I hope to see articles from Education Faculty academics, School Teachers, Educational Administrators, academics from Computer Science and Information Systems and from others interested in any aspect of the use of computers in education. It would also be good to see articles covering an even greater diversity of topics relevant to Education and Information Technologies and from an even wider range of contributors. 